\title{
Characterization of an 8-cm Diameter Ion Source System
}

\author{
Zhongmin Li ${ }^{*}$ and Clark W. Hawk ${ }^{\dagger}$ \\ University of Alabama in Huntsville, Huntsville, Al 35899 \\ Mark S. Buttweiler ${ }^{\ddagger}$ and John D. Williams ${ }^{\S}$ \\ Colorado State University, Fort Collins, CO 80523 \\ and \\ Brett Buchholtz** \\ Plasma Process Group, Loveland, CO 80537
}

\begin{abstract}
Results of tests characterizing an 8-cm diameter ion source are presented. The tests were conducted in three separate vacuum test facilities at the University of Alabama-Huntsville, Colorado State University, and L3 Communications' ETI division. Standard ion optics tests describing electron backstreaming and total-voltage-limited impingement current behavior as a function of beam current were used as guidelines for selecting operating conditions where more detailed ion beam measurements were performed. The ion beam was profiled using an in-vacuum actuating probe system to determine the total ion current density and the ion charge state distribution variation across the face of the ion source. Both current density and $\mathbf{E} \times \mathbf{B}$ probes were utilized. The ion current density data were used to obtain integrated beam current, beam flatness parameters, and general beam profile shapes. The $E \times B$ probe data were used to determine the ratio of doubly to singly charged ion current. The ion beam profile tests were performed at over six different operating points that spanned the expected operating range of the DAWN thrusters being developed at $L 3$. The characterization tests described herein reveal that the 8-cm ion source is suitable for use in (a) validating plasma diagnostic equipment, (b) xenon ion sputtering and etching studies of spacecraft materials, (c) plasma physics research, and (d) the study of ion thruster optics at varying conditions.
\end{abstract}

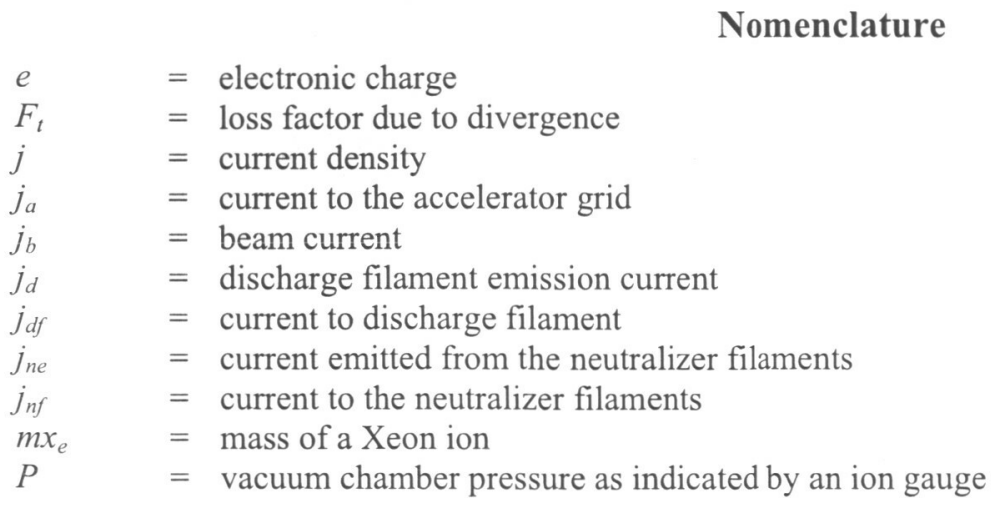

\footnotetext{
* Assistant Research Professor, Propulsion Research Center, AIAA Member.

${ }^{\dagger}$ Professor \& Director, Propulsion Research Center, AIAA Fellow.

${ }^{\ddagger}$ Research Scientist, Mechanical Engineering Department, AIAA Member.

${ }^{\S}$ Assistant Professor, Mechanical Engineering Department, AIAA Member.

${ }^{* *}$ Manager, 1714 Topaz Dr, Ste 110, AIAA Member.
}

This material is a work of the U.S. Government and is not subject to copyright protection in the United States. 
$V_{a} \quad=$ accelerator grid voltage

$V_{b} \quad=$ beam voltage

$V_{d} \quad=$ discharge voltage

\section{Introduction}

A collaborative research agreement was established between the University of Alabama-Huntsville (UAH) and Colorado State University (CSU) in Fall 2004 to develop an ion source system that could be used in ion propulsion studies. One goal of the program was to identify research on basic and applied topics related to ion thrusters and other electric propulsion devices that could be conducted in university-based vacuum test facilities, which are much less expensive to operate and more readily available compared to larger vacuum test facilities operated by governmental and commercial laboratories.

Typical constraints at universities include vacuum chamber size and/or pumping speed, which impose limitations on the size of an ion source that can be tested while simultaneously maintaining vacuum conditions that are similar to larger test facilities. For example consider a large diameter vacuum facility with a xenon pumping speed of 0.25 million liters per sec $(0.25 \mathrm{Ml} / \mathrm{s})$. A large $65-\mathrm{cm}$ diameter ion thruster producing a six ampere xenon ion beam would induce a facility pressure of $\sim 5 \times 10^{-6}$ Torr. An $8-\mathrm{cm}$ diameter ion source operating at the average ion current density of the larger source (e.g., at a beam current of $200 \mathrm{~mA}$ ) would induce a similar pressure in a facility with only $10,000 \mathrm{l} / \mathrm{s}$ of pumping speed. Note that a $200 \mathrm{~mA}$ condition for an $8-\mathrm{cm}$ ion source corresponds to an average ion current density that is about $15 \%$ greater than the $36-\mathrm{cm}$ diameter NEXT thruster [1] that is being developed by NASA Glenn for solar electric applications.

The general requirements of the $8-\mathrm{cm}$ diameter ion source included ease of installation and operation, low initial cost, inexpensive maintenance, easy portability, and good operational stability over a wide range of conditions. The Plasma Process Group (PPG) from Loveland, CO was selected to provide the ion source. They utilized Poco graphite for the grid material that was machined to aperture geometry and grid thickness that were $\sim 30 \%-50 \%$ larger than NSTAR values to ensure reliable, and trouble-free service. PPG has experience with other grid materials like pyrolytic graphite and molybdenum, and have constructed a wide range of ion optics systems from these materials that could be integrated into the ion source described herein. Hot filaments are used for the cathodes in the source, and a compact gas flow isolator is used to electrically insulate the gas feed line from the discharge chamber.

The goal of this paper is to present data on the PPG 8-cm diameter ion source (PPG-8), and then present the case for how sub-scale ion optics experiments can be conducted within small- to medium-sized vacuum test facilities at universities using this type of ion source. The apparatus and procedures used to characterize the two units are presented first where the ion source and vacuum test facilities are described along with the beam diagnostic tools. This section is followed by a results and data analysis section where the ion source performance parameters are summarized. Finally, a conclusion and future work section is presented.

\section{Apparatus and Testing}

\section{A. Current Density Probe}

A button probe enclosed within a Faraday cage was used to measure the ion current density at varying radial positions and at a fixed axial distance downstream of the PPG-8 source. The current density probe consists of a graphite button that was placed within and isolated from a cylindrical graphite body. A graphite plate with a defining aperture was affixed to the end of the probe body. The open area of the defining aperture was $0.0792-\mathrm{cm}^{2}$. The probe and probe body can be biased independently relative to the test facility ground to aide in repelling beam plasma electrons and ensuring the return to the probe surface of secondary electrons generated during ion bombardment of the button surface. An example of biasing is shown below (Fig. 1), but for the tests conducted at $\mathrm{CSU}$ and at $\mathrm{L} 3$, the probe body was kept at $-20 \mathrm{~V}$ with the probe tip at $0 \mathrm{~V}$ (i.e., test facility ground). 


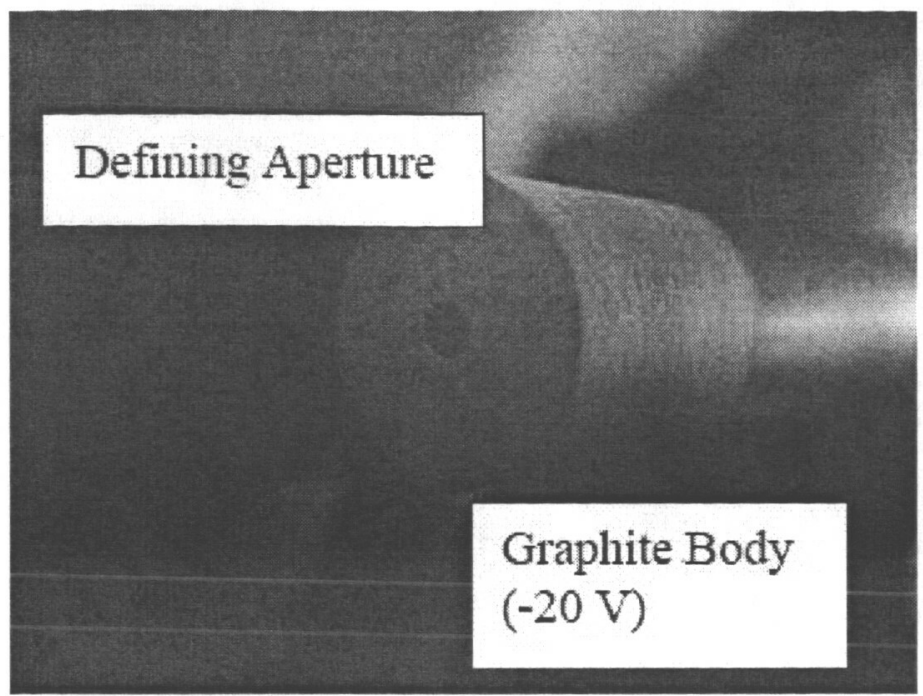

Fig. 1 Current density probe.

\section{B. ExB Probe}

A miniaturized $\mathrm{E} \times \mathrm{B}$ probe was used to measure the current of double-charged xenon ions $\left(\mathrm{Xe}^{++}\right)$and singlecharged xenon ions $\left(\mathrm{Xe}^{+}\right)$that flow from a small region of the ion optics system where this information is desired. For each region of interest, the doubly and singly charged ion currents were measured at polar angles of $\pm 30^{\circ}, 20^{\circ}$, $15^{\circ}, 10^{\circ}, 5^{\circ}$ and normal incidence. The basic purpose of an $\mathrm{E} \times \mathrm{B}$ probe is to quantify the thrust-loss factor of an actual thruster over an ideal one. Thrust losses are due to three effects that include (a) the creation of multiply charged ions in the beam, (b) ion divergence due to electric fields in the acceleration region, and (c) physical divergence of ion beamlets relative to the thruster axis due to the curved shape of some ion optics assemblies. The loss effects are accounted for by two factors: $\alpha$ and $\mathrm{F}_{\mathrm{t}}$. The $\alpha$ term accounts for the presence of multiply charged ions, while the $F_{t}$ term accounts for the two divergence effects.

The E $\times \mathrm{B}$ probe shown schematically in Fig. 2 consists of three main sections that include (a) the collimator, (b) the ExB separator, and (c) the collector region. The collimator is a cylinder with small entrance and exit apertures. Because of the small apertures, the collimator only passes ions with velocity vectors parallel to the collimator axis ( $=0.3 \mathrm{mSter}$ ). This is to ensure that only ions traveling parallel to the "aim" of the probe will be transmitted through the collimator to the ExB mass separator. The collimator is typically placed far enough downstream of an ion source under test to allow ions flowing from a small cluster of apertures (typically greater than 3 and less than 6) to be measured.

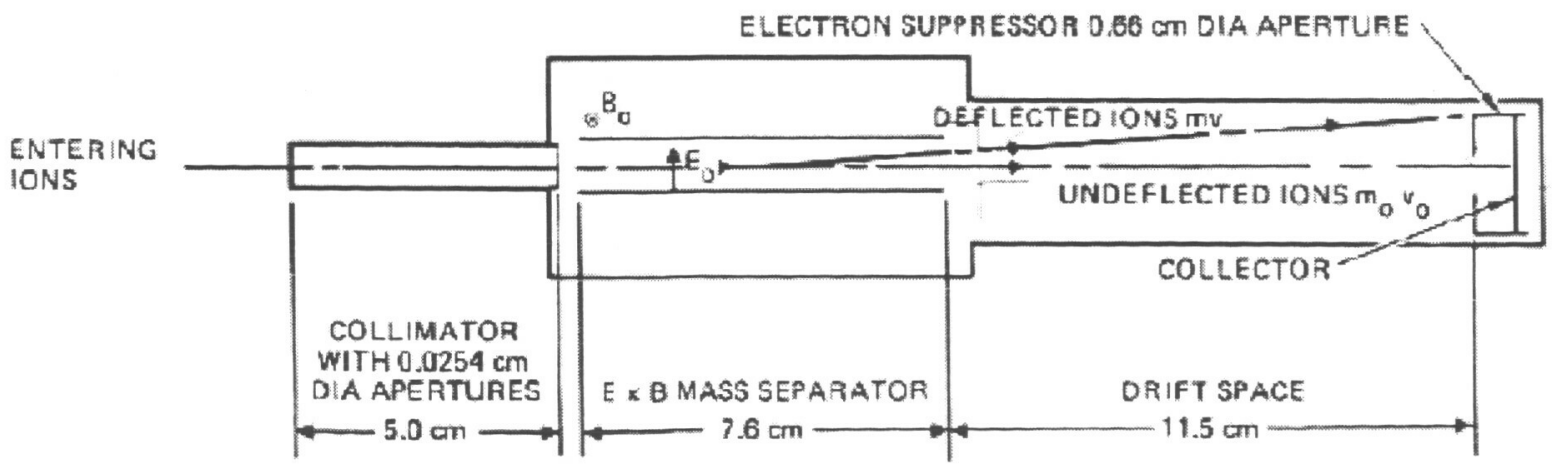

Fig. 2 Cross-section of ExB Probe showing the collimator, E x B mass separator and collector (sketch taken from Beattie[2]) 
The mass separator consists of two parallel plates, one charged positively and the other negatively, and a permanent magnet. The magnetic field (B) of the magnet is arranged such that it is perpendicular to the electric field (E) established between the plates. With this configuration, a force $[\mathrm{F}=\mathrm{q}(\mathbf{E}+\mathbf{v} \times \mathbf{B})]$ is created on an ion that deflects it from its original path, unless the velocity of the ion is exactly $|\mathbf{E}| / \mathbf{B} \mid$ in which case it will continue on its original path down the axis of the probe. Once past the mass separation region, the ions will enter the collection region where they drift either on their deflected path away from the collector (at the end of the drift space) or, if $\mathrm{v}=|\mathbf{E}| / \mathbf{B} \mid$, continue to the collector to be measured. In an ion source or thruster, single and double charged ions are accelerated through the same potential difference. This causes the doubly charged ion to have a velocity that is 1.414 times greater than the singly charged ion because both ions have nearly the same mass.

Typical $\mathrm{E} \times \mathrm{B}$ probe data corresponds to a measurement of the collector current as a function of the voltage applied between the two parallel plates in the mass separator (i.e., the pass velocity, $v=|\mathbf{E}| / \mathbf{B} \mid$ is swept by varying the electric field while the B-field is held constant). As the parallel plate voltage changes, there will be peaks in the collector current as shown in Fig. 5 that correspond to the presence of singly, doubly, triply, .charged ions.

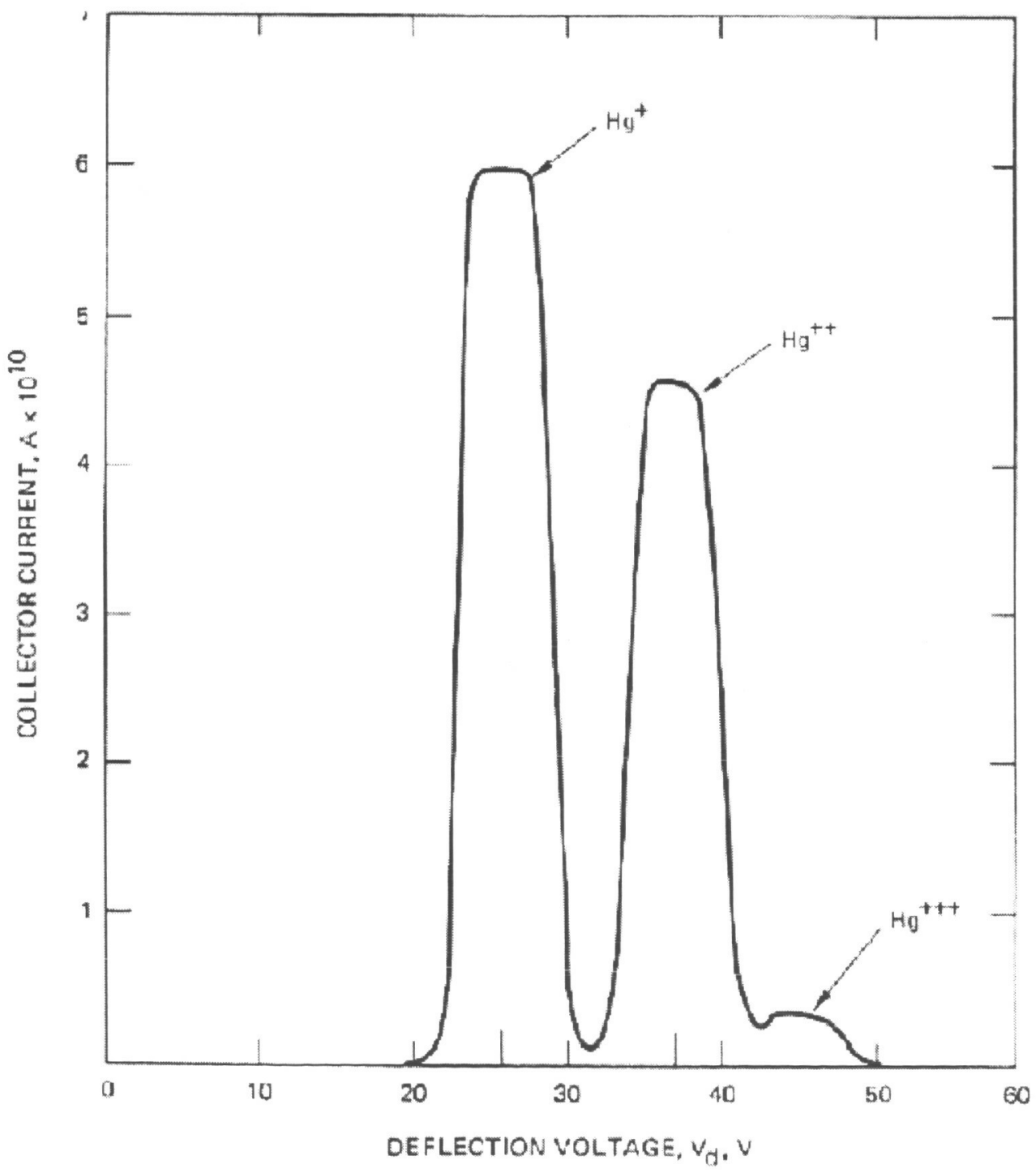

Fig. 3 Profile of $I_{\text {Collector }} v s$. $V_{\text {Deflection }}$ curve showing the presence of multiply charged ions. (Data taken from Beattie $^{2}$ ). 
A full characterization of an ion thruster with an $\mathrm{E} \times \mathrm{B}$ probe involves the simultaneous movement of the probe across the face of the thruster and the angular articulation of the probe axis relative to the thruster axis. Beattie ${ }^{2}$ presents a detailed description of this technique and how the $\mathrm{E} \times \mathrm{B}$ probe measurements are used to determine thrust loss factors due to divergence and doubly charged content of an ion beam.

\section{Positioning Stage}

The current density and ExB probes utilized at CSU and L3 are attached to one another back to back and mounted on a rotary head that allows either one to be aimed at an ion thruster under test (see Fig. 4). The rotary head, in turn, is mounted on a linear stage that is used to translate the two probes in front of the ion thruster. The horizontally pivoting head of the positioning stage allows the $\mathrm{E} \times \mathrm{B}$ probe to obtain different current measurements at alternate "views" while monitoring the thruster at the same radial position.

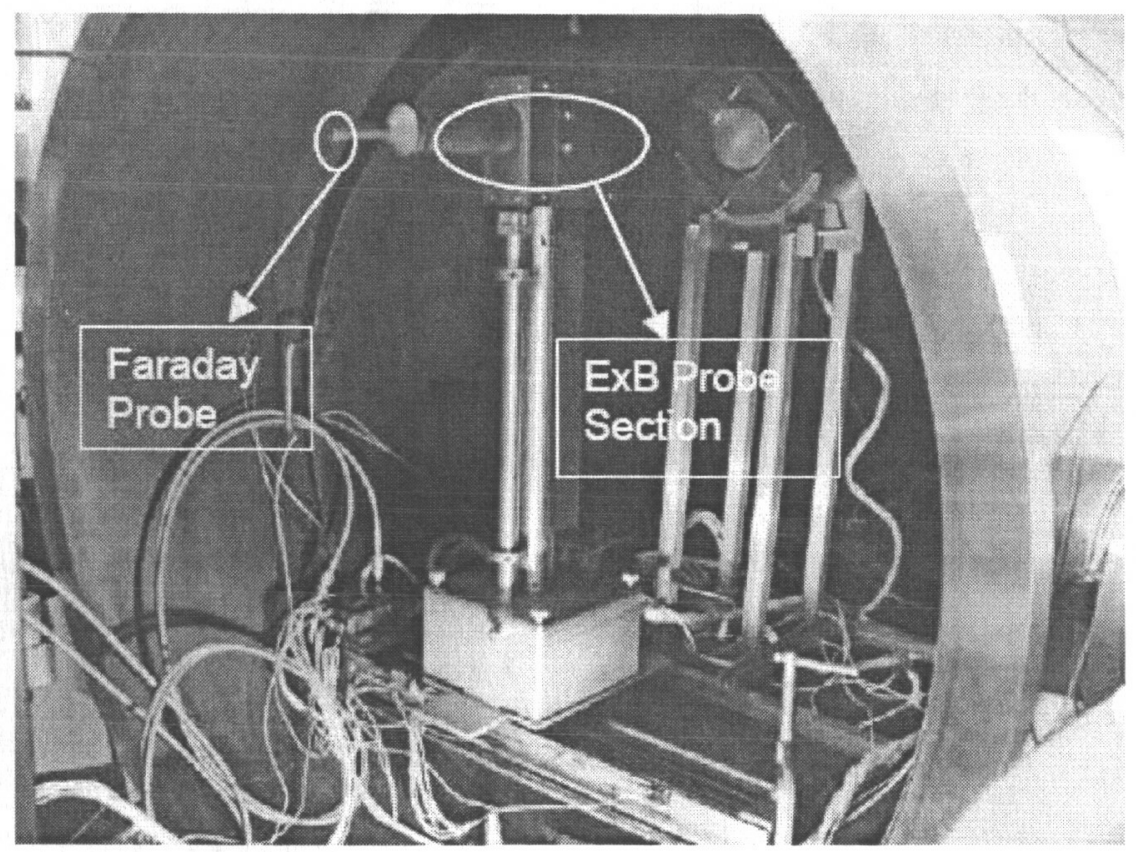

Fig. 4 Probe System as mounted in the CSU chamber.

Both the rotary and linear motor have built-in high resolution encoders and LabVIEW software was used as the interface between the motor controller the data acquisition system.

\section{Vacuum Facilities}

The test chamber at CSU is $1.2 \mathrm{~m}$ in diameter $\left(\mathrm{V}=6 \mathrm{~m}^{3}\right)$ with a pumping speed of $15,000 \mathrm{l} / \mathrm{s}$ on xenon. A Stokes roughing pump and blower are used to back a $0.9 \mathrm{~m}$ diameter diffusion pump to attain base vacuum pressures in the $10^{-7}$ Torr range. The larger, $1.8 \mathrm{~m}$ diameter $\left(4.2 \mathrm{~m}^{3}\right)$ vacuum test facility at UAH utilizes a similar pump configuration and has a Xe pumping speed of $\sim 10,000$ 1/s. At the L3 Flight Hardware Test facility in Torrance, CA a $2.7 \mathrm{~m}$ diameter $\left(23 \mathrm{~m}^{3}\right)$ chamber with a maximum Xe pumping speed of $0.25 \mathrm{Ml} / \mathrm{s}$ was used. The L3 test chamber is equipped with ten, $1.2 \mathrm{~m}$ diameter cryogenic pumps and can attain base vacuum pressures in the $10^{-8}$ Torr range. While using the L3 test chamber to characterize the PPG-8 ion source, however, only one cryo-pump with a Xe pumping speed of $25,000 \mathrm{~L} / \mathrm{s}$ was operated.

\section{E. PPG 8-cm Diameter Ion Source}

The ion source was operated using both xenon and argon gas as the propellant. The discharge plasma is created via electron bombardment processes by heating a filament cathode to the point of thermionic emission (electron emission) and accelerating the electrons into the discharge chamber using a $\sim 50 \mathrm{~V}$ power supply. The energetic discharge plasma electrons are confined using a diverging magnetic field to enhance the propellant ionization 
efficiency. Ions are extracted from the discharge chamber plasma through the apertures in the ion optics assembly and into the beam plasma. The ion beam is neutralized using a second hot filament that is placed adjacent to the ion beam. The ion optics assembly is comprised of two grids (8-cm active diameter) made of a graphite. The grids were mounted on a mounting assembly. The screen grid is held at the same high positive potential as the ion source body, and the accelerator grid is biased with a negative voltage relative to the test facility ground. Both screen and accelerator grids have 913 circular aperture holes with 0.076 " diameter. The grid material thickness is $0.060 "$ ", and the screen grid has been thinned to $\sim 0.020 "$. The grid gap was adjusted such that it was uniform to within $0.066 "$. The beam current can be adjusted from 25 to $250 \mathrm{~mA}$, and beam current density 0.5 to $4 \mathrm{~mA} / \mathrm{cm}^{2}$. The source can be operated with beam energy from 50 to $1500 \mathrm{eV}$.

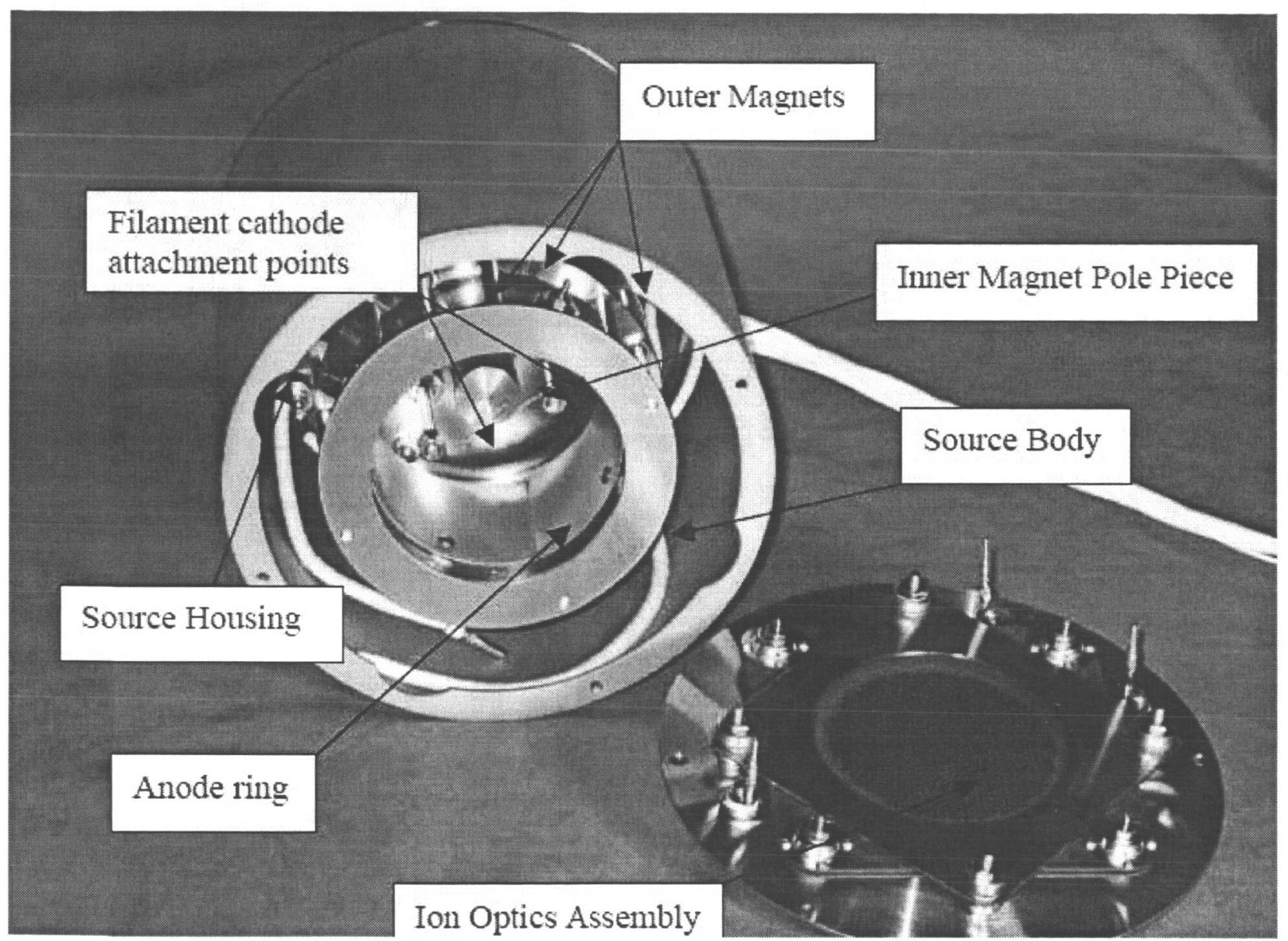

Fig. 5 PPG-8 ion source with ion optics removed to show interior.

\section{Results and Analysis}

\section{A. Ion Optics Performance Characterization}

Once the PPG-8 ion source was operating at a given beam current and voltage condition, the accelerator voltage magnitude was slowly decreased until electron backstreaming was detected. A typical backstreaming limit measurement data set is plotted in Fig. 6 for illustration purposes. For this study, the onset of backstreaming was defined to occur when the apparent beam current increased by $2.5 \%$ above the nominal beam current measured at the start of the test. It is noted that the $2.5 \%$ value is arbitrary, and either lower or higher value could have been used without significantly changing the result of the test. 


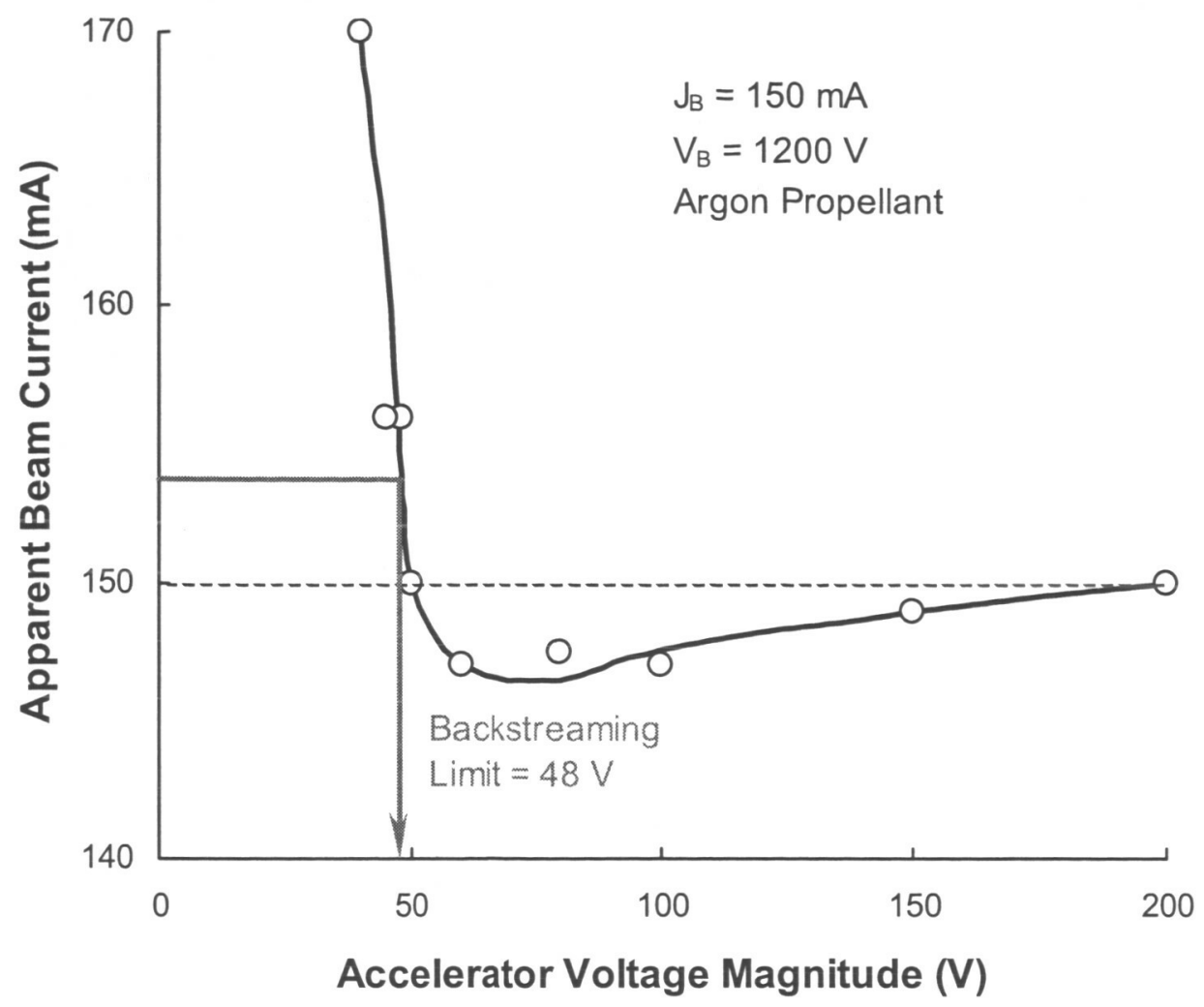

Fig. 6 Typical electron backstreaming voltage measurement for the PPG-8 source.

In addition to backstreaming measurements made as a function of beam current and voltage, tests were conducted to determine the impingement-limited total voltage over a range of beam current values. These perveance limit tests were performed by setting the beam voltage to a value $\sim 300 \mathrm{~V}$ above where direct impingement of ions on the accelerator grid would occur and slowly decreasing the beam voltage until the rate-of-rise of impingement current rose above $0.01 \mathrm{~mA} /$. A typical impingement current versus beam voltage plot is shown in Fig. 7 . For this beam current operating condition of $100 \mathrm{~mA}$, the impingement current was observed to increase rapidly as the beam voltage was decreased below $1005 \mathrm{~V}$ (i.e., the magnitude of the impingement current-to-beam voltage slope $\left(\left|\mathrm{dJ}_{\mathrm{a}} / \mathrm{dV}_{\mathrm{B}}\right|\right)$ increased above $\left.0.01 \mathrm{~mA} / \mathrm{V}\right)$.

\section{Total Voltage Limited Impingement Measurements}

Test data similar to those contained in Fig. 7 were obtained over a wide range of beam current, and the total voltage where direct impingement occurred was determined as described above. These measurements of the impingement-limited total voltage measurements are plotted in Fig. 8. For comparison, perveance limit data (corrected for argon propellant) from an $8-\mathrm{cm}$ diameter grid set with NSTAR aperture geometry is also plotted in Fig. 8. As expected, the smaller hole size of the NSTAR geometry (in comparison to the PPG- 8 grids) improves the perveance limit. Although not quite as high performance as the NSTAR-like grids, the PPG grids can be easily operated within the entire NSTAR and NEXT throttle table. 


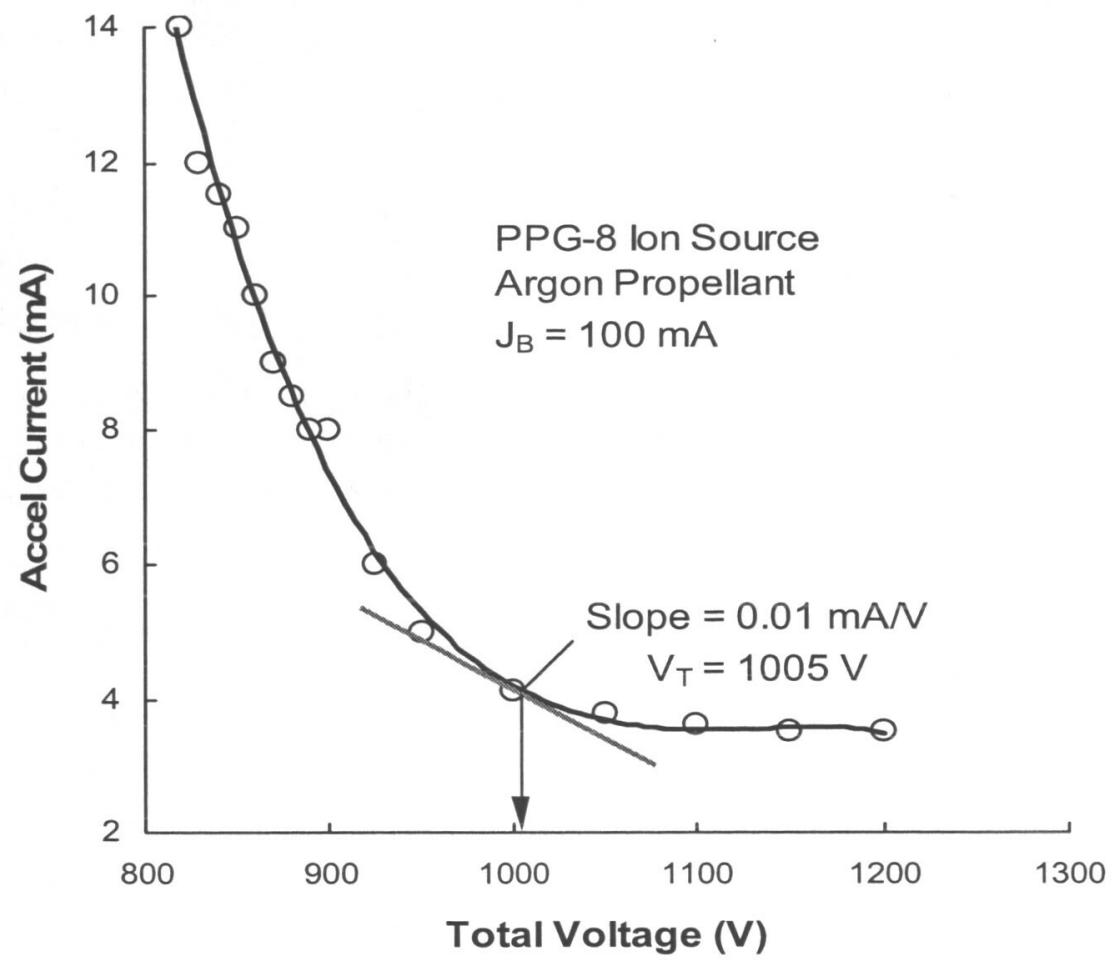

Fig. 7 Typical perveance limit measurement.

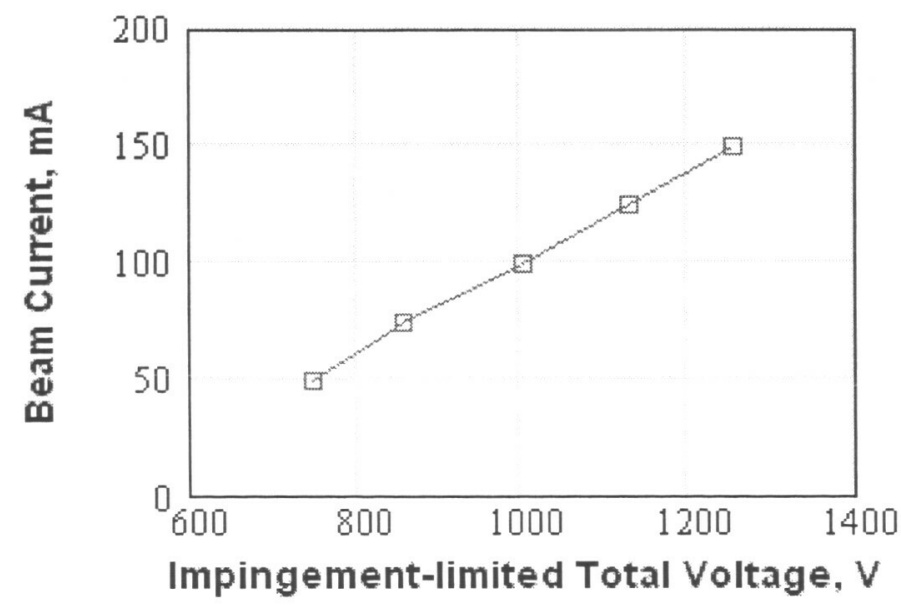

Fig. 8. Perveance limit data for the PPG-8 ion source collected with argon propellant.

2. Electron Backstreaming Measurements

Test data similar to those contained in Fig. 6 were obtained over a wide range of net voltage and beam current, and the electron backstreaming limit was determined as described above. These measurements are plotted in Fig. 9 along with similar measurements that were made using an NSTAR-like 8 -cm grid set. 


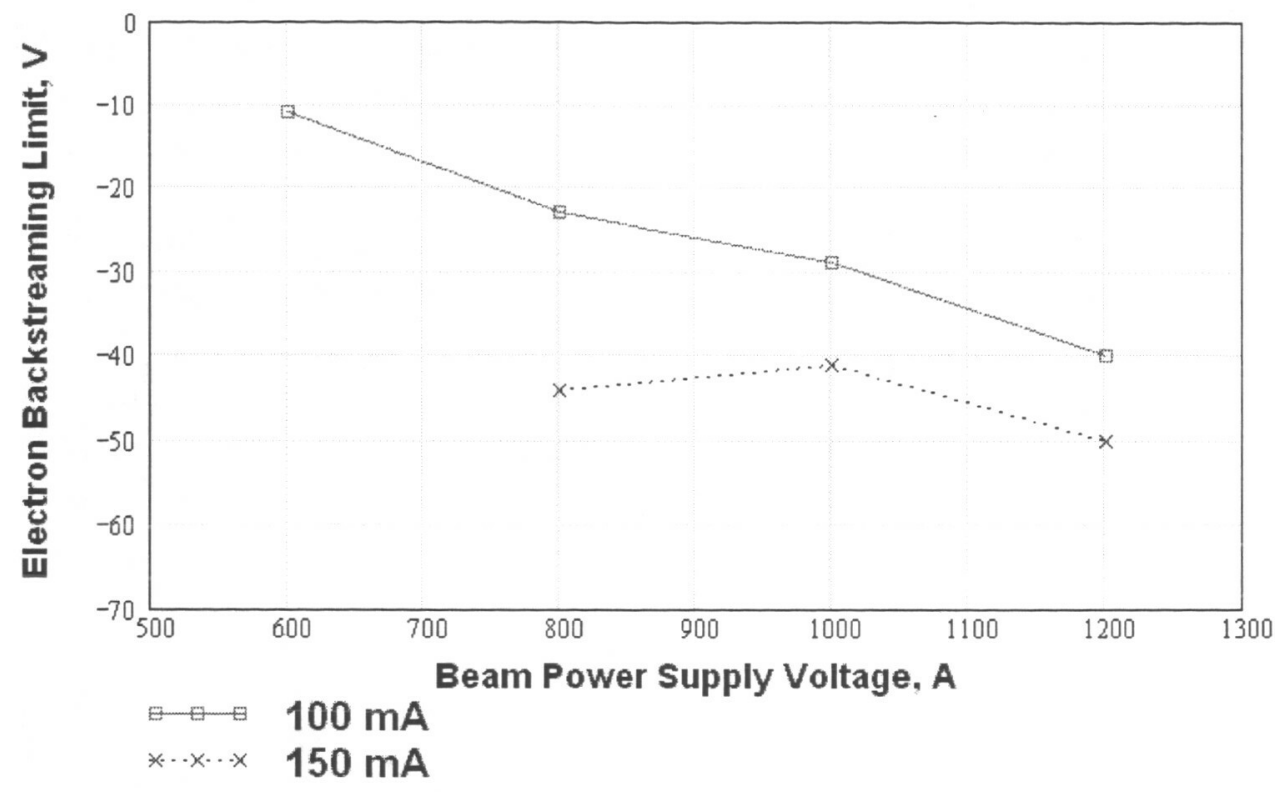

Fig. 9. Backstreaming limit data for the PPG-8 ion source.

B. Ion Beam Current Density Profiles

Fig. 10 shows the typical ion current density profile of the 8-cm ion source measured with Faraday probe.

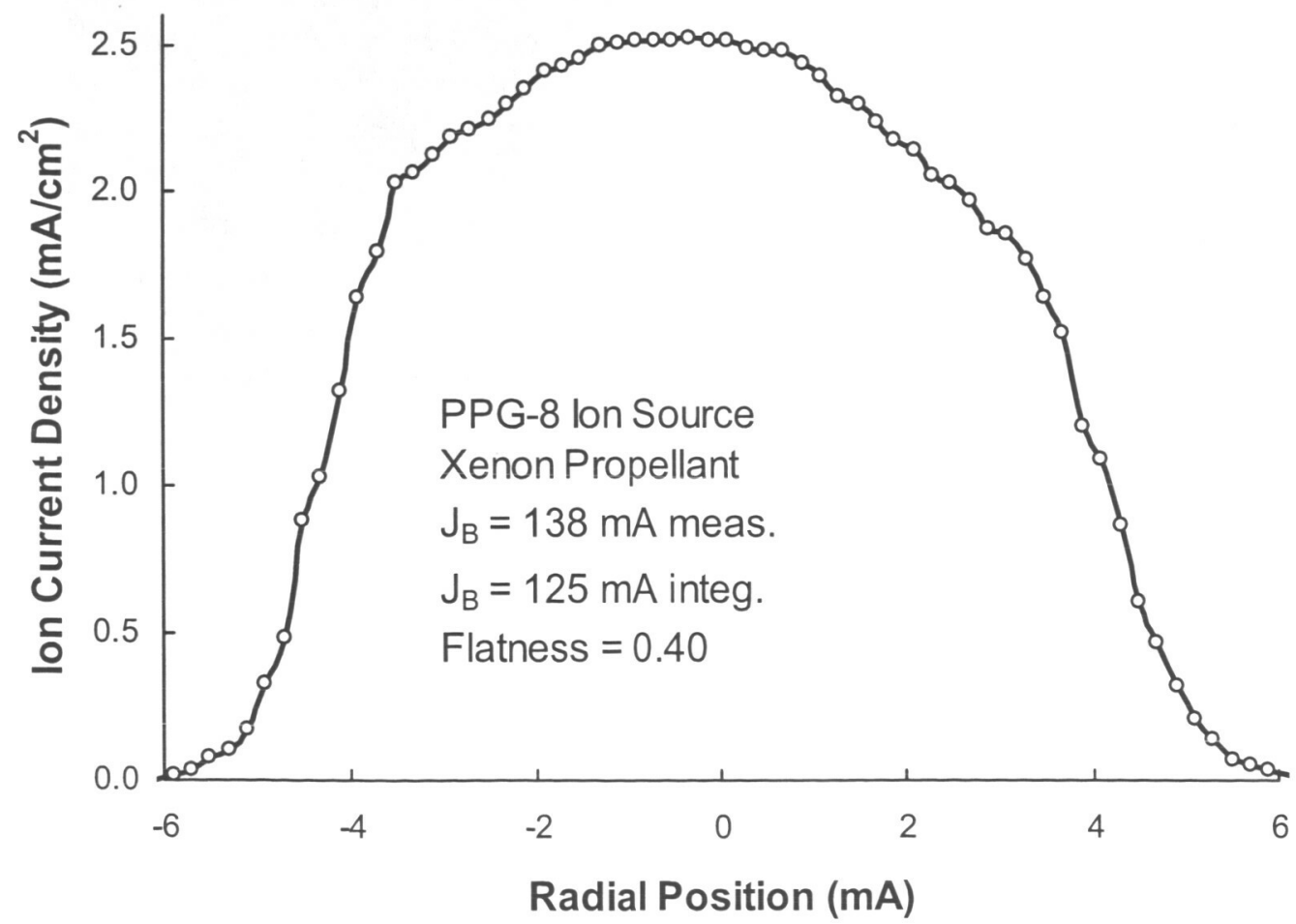

Fig. 10 Typical ion current density profile measured with Faraday probe. 


\section{Integrated Beam Current}

To obtain the desired parameters from the Faraday probe sweep, the raw probe current data was converted into current density (using the area of the probe aperture, $d=0.125$ "). The current density was then integrated over the thruster surface using the assumption of symmetry (Eq. (1)), where dr is $0.02 "$

$$
J_{\text {beam }}=\int_{-r}^{r} j d A=\sum_{-r}^{r} j \pi \cdot d r^{*}
$$

\section{Flatness}

The flatness parameter can be calculated using Eq. (2)

$$
\text { Flatness }=\frac{\mathrm{J}_{\mathrm{B}} / \mathrm{A}_{\mathrm{B}}}{\mathrm{j}_{\max }} \text {. }
$$

In Eq. (2) $J_{B}$ represents the beam current, $A_{B}$ the surface area of the active region of the ion source, and $j_{\max }$ the maximum ion current density measured with the Faraday probe.

\section{ExB Probe Data}

Figure 11 shows a typical ExB voltage sweep that was used to determine the singles and doubles sampling voltage. The collimator used in the figure below was a 0.01 " diameter collimator. Collimators of this size resulted in fairly clean voltage sweeps, as the figure shows, but were inaccurate when used in E×B angle and position sweeps, as shown in Table 2. This inaccuracy was believed to be caused due to the fact that, with the large grid holes of the $8 \mathrm{~cm}$ source, from point to point the collimator was not always viewing the same number of grid holes resulting in unreliable measurements.

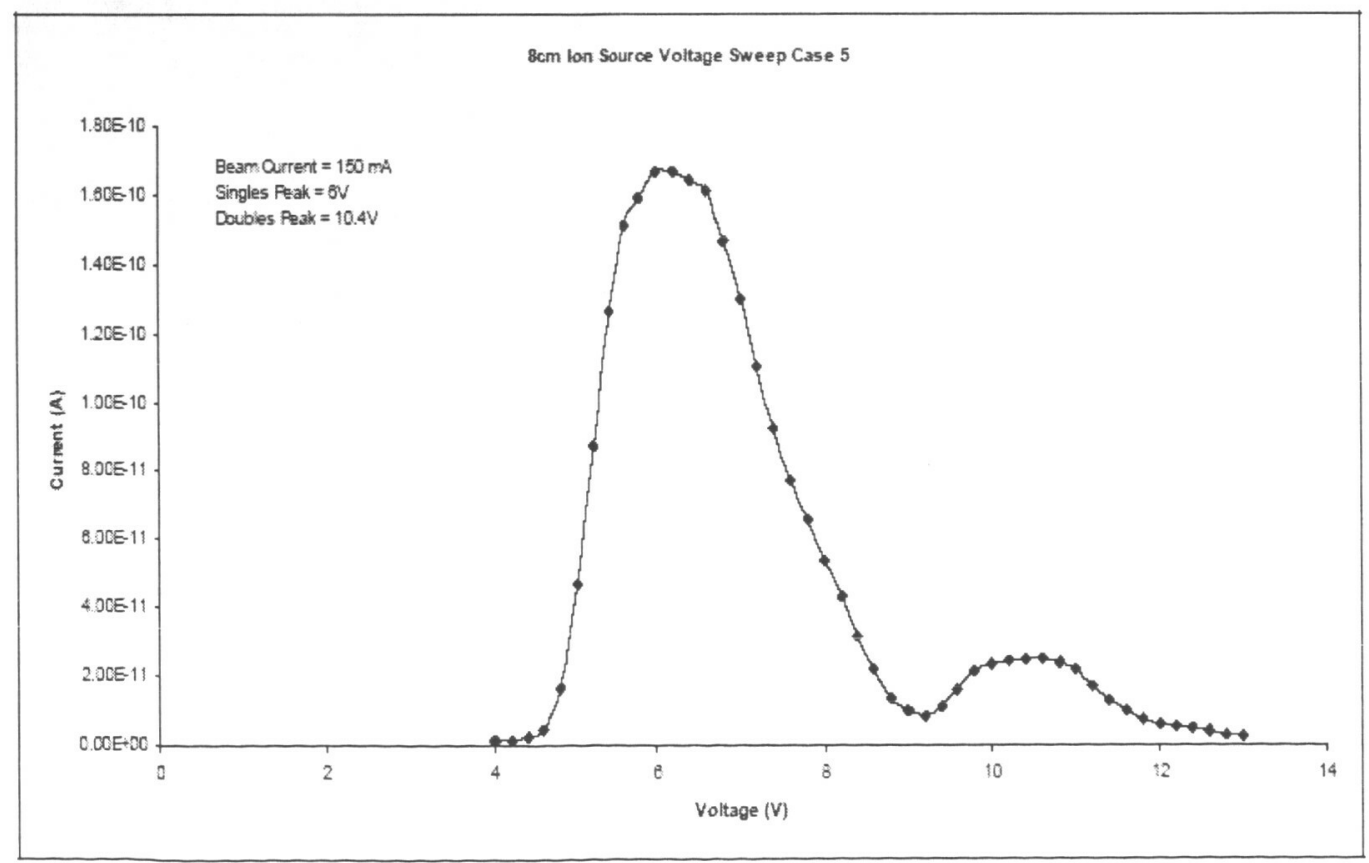

Fig. 11 Typical ExB probe scan collected with the $P P G-8$ source. 
The $\alpha$ thrust loss factor is defined in Equation 3. This factor accounts for losses associated with doubly ionized atoms. The $\mathrm{F}_{t}$ thrust loss factor accounts for beam divergence losses. Obtaining the values for $\mathrm{F}_{t}, \mathrm{~J}_{+}$and $\mathrm{J}_{++}$is calculation intensive and thus will not be examined in depth here. Of course, once $\mathrm{J}_{+}$and $\mathrm{J}_{++}$are calculated, the doubles-to-singles ratio may easily be found $\left(\mathrm{J}_{++} / \mathrm{J}_{+}\right)$. The $\mathrm{F}_{t}$ and $\alpha$ factors are related to actual thrust produced by the source by Equation 4. A propellant utilization factor was also calculated using Equation 5.

$$
\begin{gathered}
\alpha=\frac{J_{+}+\frac{\sqrt{2}}{2} J_{++}}{J_{+}+J_{++}} \\
F=\alpha F_{t} J_{b}\left(\frac{2 m_{X e} V_{b}}{e}\right)^{1 / 2} \\
\beta:=\frac{\mathrm{J}_{1}+\frac{\mathrm{J}_{2}}{2}}{\mathrm{~J}_{1}+\mathrm{J}_{2}}
\end{gathered}
$$

\section{Utilization of the PPG-8 Ion Source System to Commission the L3 Test Facility for DAWN Thruster Flight Acceptance Testing}

Tests were conducted on a PPG-8 at L3 Communications in Torrance, California, in a $2.7 \mathrm{~m}$ diameter chamber that was described earlier. The goal of these tests was to check out operation of the ion diagnostics systems before using them to characterize DAWN flight thrusters. Prior to beginning the beam profiling, the system pressure was allowed to drop to a base vacuum of $8 \times 10^{-7}$ Torr. The PPG-8 ion source was operated with xenon gas at six different test levels corresponding to equivalent DAWN thruster current density operating conditions. See Table 1 for actual beam currents and net accelerating voltages that were studied.

TABLE 1 PPG-8 operational points that are equivalent to the average current density of an NSTAR thruster to be used for the DAWN mission.

\begin{tabular}{|c|c|c|c|c|c|c|}
\hline \multicolumn{7}{|c|}{ Equivalent DAWN test level } \\
\hline & 1 & 2 & 3 & 4 & 5 & 6 \\
\hline $\mathrm{V}_{\mathrm{B}}(\mathrm{eV})$ & 1100 & 1100 & 1100 & 1100 & 1100 & 650 \\
\hline $\mathrm{J}_{\mathrm{B}}(\mathrm{mA})$ & 138 & 117 & 94 & 72 & 48 & 40 \\
\hline $\mathrm{V}_{\mathrm{A}}(\mathrm{V})$ & -250 & -250 & -180 & -180 & -180 & -180 \\
\hline
\end{tabular}

The Faraday probe was used to profile the beam current density $2.5 \mathrm{~cm}$ downstream of the ion source. The probe was scanned across the ion beam in $0.2 \mathrm{~cm}$ steps. The beam center was determined by plotting (overlaying) the left and right sides of the beam, and adjusting the radial offset position until the downward slopes of the two halves overlaid in the best alignment. Once the $\mathrm{r}=0$ position was determined, a 6 -th order polynomial curve fit was then made to the data $\left(j(r)=A_{0}+A_{1} r+A_{2} r^{2}+\ldots\right)$. The curve fit equation was integrated to determine the ion beam current:

$$
J_{B}=\sum_{i=0}^{n} 2 \pi A_{i} \frac{r_{o}^{i+2}}{i+2}
$$


In Eq. (2), $\mathrm{J}_{B}$ represents the ion beam current and $\mathrm{r}_{0}$ is the radial position where the current density profile is observed to drop to $\sim$ zero $\mathrm{mA} / \mathrm{cm}^{2}$. At Test Level 1, (see Table 1) the PPG-8 ion source was operated at the following chamber and source conditions: Pressure $4.1 \times 10^{-6}$ Torr, flow rate $8.6 \mathrm{sccm}$, discharge voltage $55 \mathrm{v}$, and discharge current $430 \mathrm{~mA}$. Faraday data analysis yielded an integrated ion beam current $\left(\mathrm{J}_{\mathrm{B}}\right)$ of $125 \mathrm{~mA}$, which was $9.4 \%$ lower than the beam current indicated by the screen power supply meter.

Tests conducted at CSU used a separately manufactured PPG-8 ion source with the following chamber and source parameters: Pressure $2.5 \times 10^{-5}$ Torr, flow rate $3.0 \mathrm{sccm}$, beam voltage $1200 \mathrm{~V}$, accelerator voltage $-400 \mathrm{~V}$, beam current $150 \mathrm{~mA}$, discharge voltage $70 \mathrm{~V}$, and discharge current $520 \mathrm{~mA}$. The current density profile is shown in Fig. 13.

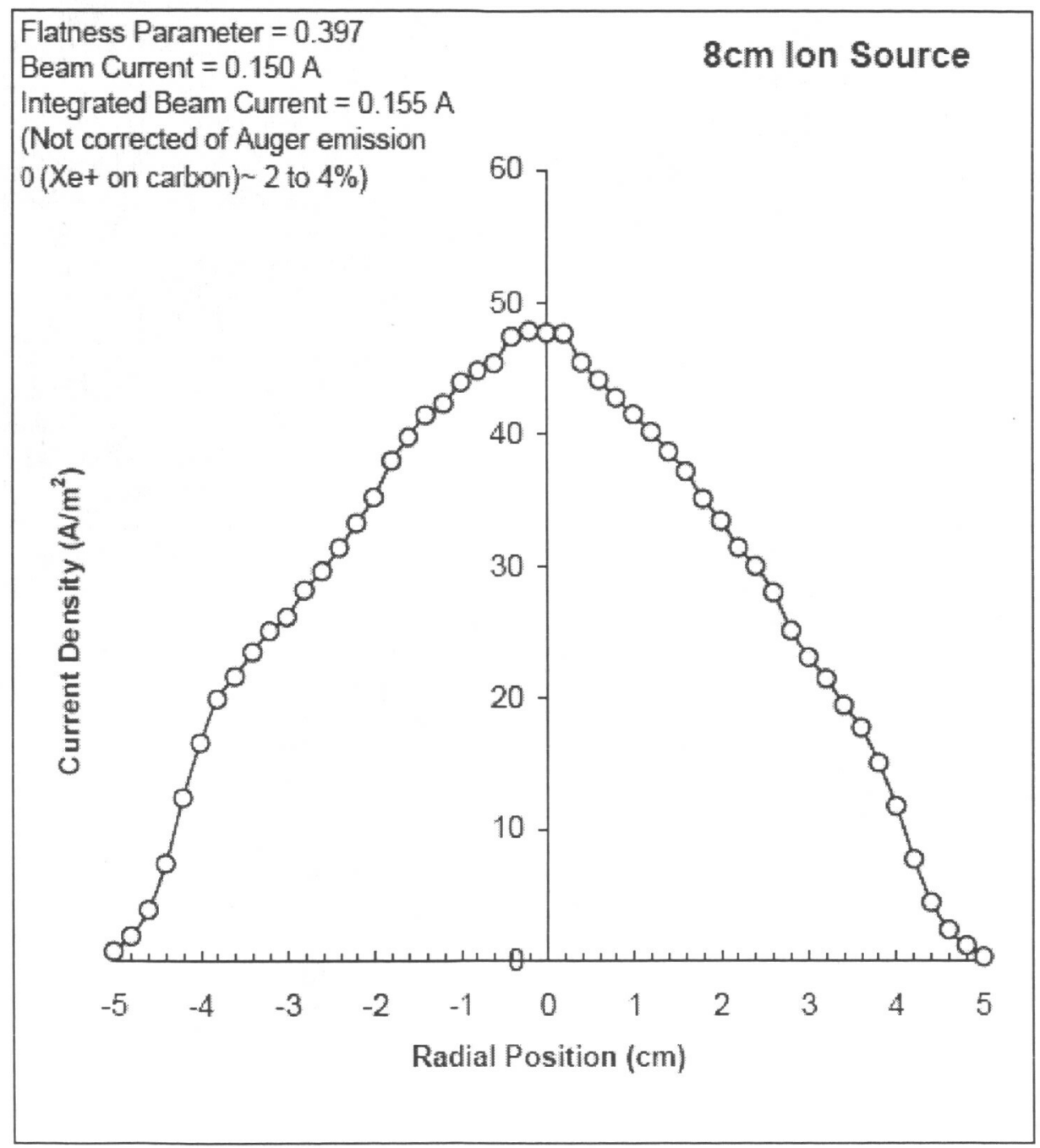

Fig. 13 Ion current density profiles measured at CSU.

The measurements taken at L3 were analyzed and the results tabulated in Table 3. Theses measurements can be compared to data collected at CSU that are listed in Table 4. 
TABLE 3 Test results collected at L3 on the PPG-8 ion source.

\begin{tabular}{|c|c|c|c|c|c|c|}
\hline Test Point & $\mathrm{V}_{\mathrm{B}}(\mathrm{V})$ & $\begin{array}{c}\mathrm{J}_{\mathrm{B}} \text { Actual } \\
(\mathrm{mA})\end{array}$ & $\begin{array}{c}\mathrm{J}_{\mathrm{B}} \text { Integrated } \\
(\mathrm{mA})\end{array}$ & $\begin{array}{c}\text { \% error } \\
\text { Flatness }\end{array}$ & $\mathrm{j}++/ \mathrm{j}+\mathrm{Max}$ \\
\hline 1 & 1100 & 138 & 125 & -9.2 & 0.399 & \\
\hline 2 & 1100 & 119 & 109 & -6.6 & 0.479 & 0.095 \\
\hline 3 & 1100 & 95 & 87.4 & -7.0 & 0.398 & \\
\hline 4 & 1100 & 71 & 63.8 & -13.8 & 0.332 & \\
\hline 5 & 1100 & 48 & 41.1 & -14.3 & 0.305 & 0.1023 \\
\hline 6 & 650 & 40 & 35.2 & -12.0 & 0.339 & \\
\hline
\end{tabular}

TABLE 4 Test results collected at CSU on the PPG-8 ion source.

\begin{tabular}{|r|c|c|c|c|c|c|}
\hline Test & $\mathrm{V}_{\mathrm{B}}(\mathrm{V})$ & $\begin{array}{c}\mathrm{J}_{\mathrm{B}} \text { Actual } \\
(\mathrm{mA})\end{array}$ & $\begin{array}{c}\mathrm{J}_{\mathrm{B}} \text { Integrated } \\
(\mathrm{mA})\end{array}$ & $\begin{array}{l}\text { \% Error } \\
\text { Flatness }\end{array}$ & $\mathrm{j}++/ \mathrm{j}+\mathrm{Max}$ \\
\hline 1 & 1100 & 75 & 63 & 16 & 0.276 & 0.81 \\
\hline 2 & 1100 & 100 & 94 & 6.0 & 0.390 & 0.127 \\
\hline 3 & 1100 & 150 & 143 & 4.7 & 0.400 & 0.10 \\
\hline 4 & 1200 & 100 & 99 & 1.0 & 0.394 & 0.636 \\
\hline 5 & 1200 & 150 & 155 & -3.3 & 0.397 & 0.638 \\
\hline 6 & 1000 & 117 & 106 & 9.4 & 0.337 & 0.060 \\
\hline 7 & 1000 & 75 & 75 & 0.0 & 0.366 & 0.062 \\
\hline 8 & 1000 & 100 & 94 & 6.0 & 0.343 & 0.067 \\
\hline
\end{tabular}

\section{Conclusion}

The PPG-8 ion source was characterized over a range of operating conditions. Specific tests were performed at average current densities that were equivalent to the test levels that are being used for the acceptance tests of $30-\mathrm{cm}$ diameter NSTAR ion engines intended for the DAWN mission. Ion current density profiles indicate that the PPG8 ion beam is very symmetrical. The flatness parameter was measured to be $\sim 0.4$. Measurements were taken in the vacuum test facilities at $\mathrm{UAH}, \mathrm{CSU}$, and L3, and these tests reveal that the PPG-8 ion source is suitable for use in xenon ion sputtering and etching of spacecraft materials, plasma physics research, and the study of ion thruster optics at varying conditions.

The lengthy time frames needed to install, bake-out and condition flight-grade ion thrusters can make the testing and verification of diagnostic tools difficult and expensive. Ease of set up, simple maintenance and excellent repeatability make the PPG-8 ion source an ideal tool for use in calibrating diagnostic probes, or material sputtering in ion thruster test chambers. If incorporated at all electric propulsion test facilities, it could also be used for comparing and verifying data from one facility to another, thus providing an excellent means of ensuring diagnostic system calibration throughout the EP community.

$\mathrm{UAH}$ is working on establishing automated operation and power supply control for the ion source system A high-speed probe position system with a complete set of electrostatic probes are under construction for fast probing the ion thruster plume and discharge chamber. Future studies on ion thruster lifetime issues are planned. The three major accumulated erosion modes in ion thruster, accelerator grid erosion, screen grid erosion and cathode end of life, can all be traced to the ion impact on these structures. Especially, the accelerator grid erosion is mostly due to the sputtering by the charge-exchange (CEX) ions. A gridded retarding pressure sensor $[6,7]$ will be developed to obtain the CEX ion fraction by the measure of the high kinetic energy neutral flux presented in different locations in the plume. 


\section{Acknowledgments}

This work was supported by NASA Grant NCC8-200 with NASA MSFC with Mary Trawek as the COTR for NASA and Dr. Clark W. Hawk as Principal Investigator for the UAH Propulsion Research Center. The authors acknowledge the contributions of the UAH, CSU and PPG personnel for the supports in preparing the facility and performing the tests.

\section{References}

'G.C. Soulas, M.T. Domonkos, and M.J. Patterson, "Performance Evaluation of the NEXT Ion Engine," 39th Joint Propulsion Conference, AIAA-2003-5278, Huntsville, AL, July 20-23, 2003.

${ }^{2}$ Beattie, J.R. "Extended Performance Technology Study: 30-cm Thruster". NAS 3-21943 Final, 1983. SuDoc Call Number: NASA 1.26:168259

${ }^{3}$ Williams, G.J., Jr., Domonkos, M.T. and Chavez, J. M. "Measurement of Doubly Charged Ions in Ion Thruster Plumes," IEPC-01-310, 27th International Electric Propulsion Conference, Pasadena, CA, 15-19 October, 2001.

${ }^{4}$ Soulas, G.C., Haag, T.W., and Patterson, M.J., "Performance Evaluation of $40 \mathrm{~cm}$ Ion Optics for the Next Ion Engine" AIAA paper 2002-3834, July 2002.

${ }^{5} \mathrm{Haag}$, T.W., and Soulas, G.C "Performance of $8 \mathrm{~cm}$ Pyrolytic-Graphite Ion Thruster Optics," AIAA paper 2002-4335, July 2002.

${ }^{6}$ King, L. B., Gallimore, A. D., and Marrese, C. M., "Transport Property Measurements in the Plume of an SPT100 Hall Thruster," Journal of Propulsion and Power, Vol. 14, No. 3, May-June 1998, 327- 335.

${ }^{7}$ King, L. B., "Transport-property and Mass Spectral Measurements in the Plasma Exhaust Plume of a Hall-effect Space Propulsion System," Ph.D. Dissertation, University of Michigan, 1998. 